\title{
Bilateral antegrade cerebral perfusion during aortic dissection surgery: If no harm, then why not?
}

\author{
Hiroo Takayama, $\mathrm{MD}, \mathrm{PhD},{ }^{\mathrm{a}}$ and Michael A. Borger, $\mathrm{MD}, \mathrm{PhD}^{\mathrm{b}}$
}

\footnotetext{
From the ${ }^{\mathrm{a} D e p a r t m e n t ~ o f ~ S u r g e r y, ~ C o l u m b i a ~ U n i v e r s i t y ~ M e d i c a l ~ C e n t e r, ~ N e w ~ Y o r k, ~ N Y ; ~ a n d ~ t h e ~}{ }^{\mathrm{b}}$ Department of Cardiac Surgery, Leipzig Heart Center, Leipzig, Germany.

Disclosures: Authors have nothing to disclose with regard to commercial support.

Received for publication April 8, 2017; accepted for publication April 12, 2017; available ahead of print May 11, 2017.

Address for reprints: Michael A. Borger, MD, PhD, Leipzig Heart Center, Struempellstrasse 39, 04289 Leipzig, Germany (E-mail: michael.borger@helios-kliniken.de).

J Thorac Cardiovasc Surg 2017;154:776-7

$0022-5223 / \$ 36.00$

Copyright (c) 2017 by The American Association for Thoracic Surgery

http://dx.doi.org/10.1016/j.jtcvs.2017.04.030
}

In the current issue of the Journal, Tong and colleagues ${ }^{1}$ retrospectively compare outcomes in patients undergoing unilateral antegrade cerebral perfusion (ACP) versus bilateral ACP (bACP) during total aortic arch replacement for type A aortic dissection. The rate of total aortic arch replacement was high in their series (ie, $58 \%$ of all patients with type A dissection), and the frozen elephant trunk procedure was performed in nearly all these patients, reflecting the aggressive approach and skilled nature of the surgical team. Tong and colleagues ${ }^{1}$ found nonsignificantly reduced mortality $(11.6 \%$ vs $20.7 \%, P=.075)$ and rate of permanent neurologic dysfunction $(8.4 \%$ vs $16.9 \%, P=.091)$ in the bACP group, likely because of the relatively small sample size of this single-center study. It is important to note, however, that both methods of cerebral protection have been performed at the center of Tong and colleagues ${ }^{1}$ since 2009. During this period, it is likely that bACP was more selectively used for patients who required more complex total aortic arch replacement procedures. The true reductions in permanent neurologic dysfunction rate and mortality for patients with bACP thus may have been underestimated.

The argument between unilateral ACP and bACP during aortic arch surgery has been debated for years. In this regard, a randomized trial is direly needed. Until this is performed, however, we rely on retrospective evidence. Like Tong and colleagues, ${ }^{1}$ we are strong proponents of bACP during complex aortic arch procedures. We sincerely believe that the possible benefits of this technique far outweigh the possible disadvantages. We have performed hundreds of aortic arch procedures with bACP without any obvious mechanical complications of the technique, such as local dissection or injury of the supra-aortic vessels. Although we use a method that is significantly different from that used by Tong and colleagues $^{1}$ (ie, axillary cannulation with clamping of the brachiocephalic artery and careful insertion of balloon-tipped perfusion catheters in the left carotid artery with or without the left subclavian artery), the end result-effective bilateral cerebral perfusion-is the same.

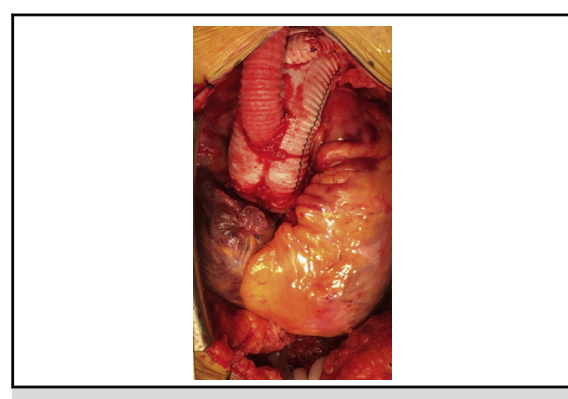

Total arch reconstruction for type A aortic dissection.

Central Message

The debate of unilateral versus bilateral antegrade cerebral perfusion (bACP) continues. Tong and colleagues demonstrate that bACP for complex type A aortic dissection surgery is safe and possibly superior.

See Article page 767
Several arguments have been made against the routine use of bACP. Manipulation of the base of the supraaortic vessels may increase the risk of distal embolization, but most patients with acute type A dissection do not have extensive atherosclerosis. ${ }^{2}$ Another argument is that a complete circle of Willis is present in most patients. ${ }^{3}$ Even in patients with an intact circle of Willis, however, bACP should result in more effective cerebral perfusion by eliminating backflow and possible steal phenomenon through the open left common carotid and left subclavian ostia. Another argument against bACP is its supposedly complex nature. As Tong and colleagues $^{1}$ have demonstrated, however, bACP can be used effectively without any significant increases in circulatory arrest, myocardial ischemia, or cardiopulmonary bypass times-markers of feasibility. It is also our opinion that bACP can be implemented and routinely used during aortic arch surgery with a very short learning curve, particularly in large-volume aortic centers.

It is challenging to find direct evidence of the superiority of bACP in the literature, simply because all studies to date are retrospective in nature, and bACP has usually been reserved for patients requiring more complex operations with longer circulatory arrest times. A meta-analysis reporting on more than 6000 patients from 32 publications, however, showed significantly 
decreased rates of both permanent and temporary neurologic dysfunction in patients undergoing aortic arch surgery with bACP. ${ }^{4}$

Hippocrates has been credited as saying, "Make a habit of two things: to help; or at least do no harm." By using bACP, we may accomplish both of these goals. Although definitive proof that bACP is superior to unilateral ACP is still lacking, the important question is this: If it does not cause any obvious harm, then why not?

\section{References}

1. Tong G, Zhang B, Zhou X, Tao Y, Yan T, Wang X, et al. Bilateral versus unilateral antegrade cerebral perfusion in total arch replacement for type A aortic dissection. J Thorac Cardiovasc Surg. 2017;154:767-75.

2. Barbetseas J, Alexopoulos N, Brili S, Aggeli C, Chrysohoou C, Frogoudaki A, et al. Atherosclerosis of the aorta in patients with acute thoracic aortic dissection. Circ J. 2008;72:1773-6.

3. Merkkola P, Tulla H, Ronkainen A, Soppi V, Oksala A, Koivisto T, et al. Incomplete circle of Willis and right axillary artery perfusion. Ann Thorac Surg. 2006;82:74-9.

4. Angeloni E, Melina G, Refice SK, Roscitano A, Capuano F, Comito C, et al. Unilateral versus bilateral antegrade cerebral protection during aortic surgery: an updated meta-analysis. Ann Thorac Surg. 2015;99:2024-31. 